Research Journal of Pharmacology 4 (2): 38-44, 2010

ISSN: $1815-9362$

(C) Medwell Journals, 2010

\title{
Evaluation of Fungal Taxol Isolated from an Endophytic Fungus Pestalotiopsis pauciseta VM1 Against Experimentally Induced Breast Cancer in Sprague Dawley Rats
}

\author{
${ }^{1} \mathrm{R}$. Vennila, ${ }^{2} \mathrm{~S} . \mathrm{V}$. Thirunavukkarasu and ${ }^{1} \mathrm{~J}$. Muthumary \\ ${ }^{1}$ Centre for Advanced Studies in Botany, University of Madras, Guindy Campus, \\ Chennai 600-025, Tamil Nadu, India \\ ${ }^{2}$ Department of Pharmacology, C.L. Baid Metha College of Pharmacy, \\ Chennai 600-097, Tamil Nadu, India
}

\begin{abstract}
The present study was carried out for chemopreventive effect of fungal taxol derived from an endophytic fungus, Pestalotiopsis pauciseta VM1 isolated from a medicinal plant Tabebuia pentaphylla Hemsl. The biochemical parameters like blood urea, serum uric acid, creatinine, haemoglobin, protein, tryglycerides, total cholesterol and phospholipids were estimated in control and experimental groups. Based on the results, the fungal taxol were found to be best against 7,12 dimethyl benz (a) anthracene induced mammary tumors in Sprague Dawley rats.
\end{abstract}

Key words: 7,12 dimethyl benz (a) anthracene, Sprague Dawley rats, Pestalotiopsis pauciseta, breast cancer, fungal taxol

\section{INTRODUCTION}

Cancer is a growing public menace and $>6$ million new cases of this disease are reported every year. Breast cancer is one of the most common types of cancers and cause of cancer death in women worldwide. Women with early stage breast cancer may have breast-sparing surgery followed radiation therapy. Many women with stage III and IV cancer have chemotherapy or hormonal therapy to destroy cancer cells and control the disease with radiation. The successful therapy of breast cancer will have to identify natural products that have significant chemotherapeutic and preventive potential without toxic effects. The aim of the present study is to find out an alternative and effective drug

The taxol has been used to treat tumors like the colon, rectum carcinoma, metastatic breast cancer, lung cancer, tumors in head and neck and malignant melanotic cancer and so on (Croom, 1995). Taxol, a highly functionalised diterpene was first discovered from the bark of western yew (Taxus brevifolia), a relatively rare and slow growing tree by Wani et al. (1971) and the yield is very low (0.01-0.03\%).

Efforts were therefore, made by several research groups to address the supply problem of taxol in a variety of ways. A new possibility to produce taxol in a cheaper way is industrial fermentation has come from the discovery that some endophytic fungi belonging to different genera such as Taxomyces, Pestalotiopsis, Alternaria and Periconia (Stierle et al., 1993; Li et al., 1998a, b). Hence the present study was taken up to prove the chemopreventive effect of fungal taxol isolated from an endophytic fungus, Pestalotiopsis pauciseta Sacc. VM1 against 7, 12 dimethyl benz (a) anthracene induced mammary tumors in Sprague Dawley rats.

\section{MATERIALS AND METHODS}

Growth of the fungi in liquid media: The test fungus were grown in $3 \mathrm{~L}$ Hopkins flasks containing $1500 \mathrm{~mL}$ of MID medium. The cultures were incubated for 18 days.

Extraction of taxol: The extraction procedure by Strobel et al. (1996). After the incubation period, the cultures were filtered through four layers of cheese cloth to remove mycelia. To the culture filtrate, $0.25 \mathrm{~g} \mathrm{Na}_{2} \mathrm{CO}_{3}$ was added with frequent shaking in order to reduce the amount of fatty acids that may contaminate taxol in the culture. Then, the culture filtrate was extracted with two equal volumes of solvent dichloromethane. The organic phase was collected and the solvent was then removed by evaporation under reduced pressure at $35^{\circ} \mathrm{C}$ using rotary vacuum evaporator. The dry solid residue was re-dissolved in methanol for the subsequent separation and the fungal taxol was confirmed by spectral and analytical methods.

Corresponding Author: R. Vennila, Centre for Advanced Studies in Botany University of Madras, Guindy Campus, Chennai 600-025, Tamilnadu, India 
Ethical clearance: The Institutional Animal Ethical Committee approved experimental design performed in this study for the use of Sprague Dawley rats as an animal model for cancer activity (IAEC No. 03/014/08).

Animals: Healthy female Sprague Dawley rats purchased from National Institute of Nutrition, Hyderabad, India were selected for the present research. The animal house was well ventilated and animals had $12 \pm 1 \mathrm{~h}$ day and night schedule. The animals were housed in large spacious hygienic cages during the course of the experimental period. The animals were fed with pellet feed supplied by $\mathrm{M} / \mathrm{s}$ Hindustan Liver Ltd, (Bangalore, India) and water ad libitum.

Experimental design: The experimental design of the present research was like the following five groups consisting of 6 animals in each group:

Group I: Normal healthy animals served as controls.

Group II: Rats was induced mammary carcinoma with 7 , 12 , dimethylbenz (a) anthracene $25 \mathrm{mg} \mathrm{kg}^{-1}$ dissolved in $1 \mathrm{~mL}$ of olive oil, through gastric incubation (Welsch, 1985).

Group III: Mammary carcinoma was induced in Group III animals also (as in Group II) and treated with fungal taxol ( $8 \mathrm{mg} \mathrm{kg}^{-1}$ body weight in $1 \mathrm{~mL}$ saline) once in a week for 4 weeks, intraperitoneally.

Group IV: Mammary carcinoma was induced in Group IV animals also (as in Group II) and treated with Paclitaxel ( $1 \mathrm{mg} \mathrm{kg}^{-1}$ body weight in $1 \mathrm{~mL}$ saline) once in a week for 4 weeks intraperitoneally.

Group V: Drug control animals received fungal taxol alone in the same dosage as in Group III animals.

At the end of experimental period, the overnight fasted animals were sacrificed by cervical decapitation. Blood was collected from the rats. Serum was obtained after blood coagulation and centrifugation at $5000 \mathrm{rpm}$ for 15 min to obtain a clear supernatant (serum) which was stored at $-70^{\circ} \mathrm{C}$ until its use for further biochemical analysis. Breast tissues were immediately excised from the animals. A $10 \%$ homogenate was prepared in Tris- $\mathrm{HCl}$ buffer $0.1 \mathrm{M} \mathrm{pH} 7.4$ using Homoginiser. The kidney and liver tissue homogenates were used for further biochemical analysis.

Biochemical and histopathalogical studies: The blood urea, serum uric acid and serum creatinine activity were estimated by the method of Natelson et al. (1951), Caraway (1963) and Slot (1965). The activity of triglycerides, total cholesterol and phospholipids was estimated by the method of Rice (1970) and Van Handel (1961), Parekh and Jung (1970) and Rouser et al. (1970). Protein was measured by the method of Lowry et al. (1951). Haemoglobin was estimated by the method of Drabkin and Austin (1932). Kidney and liver tissue was fixed in 10\% buffered formalin, embedded in paraffin using a conventional automated system. The blocks were cut to obtain $5 \mu \mathrm{M}$ thick sections and stained with haemotoxylin-eosin. Serial paraffin sections of each tissue image were captured by light microscopy (Kumaraguruparan et al., 2007).

Statistical analysis: The experimental results were expressed as mean \pm Standard Deviation (SD). Data was analysed by the method of one way Analysis of Variance (ANOVA) followed by Tukey multiple comparison was carried out to compare the mean value of different groups by using SPSS 7.5 student version.

\section{RESULTS}

Effect of fungal taxol on the levels of blood urea, serum uric acid and creatinine in control and experimental groups: The levels of blood urea, serum uric acid were clearly shown in Fig. 1 and 2. Blood urea, serum uric acid levels were significantly reduced in Group II cancer induced animals. The levels were increased in fungal taxol and commercial taxol treated animals (Group III and IV). Whereas, the Group V drug alone rats the levels of blood urea, serum uric acid were similar to the control groups. The serum creatinine level is significantly

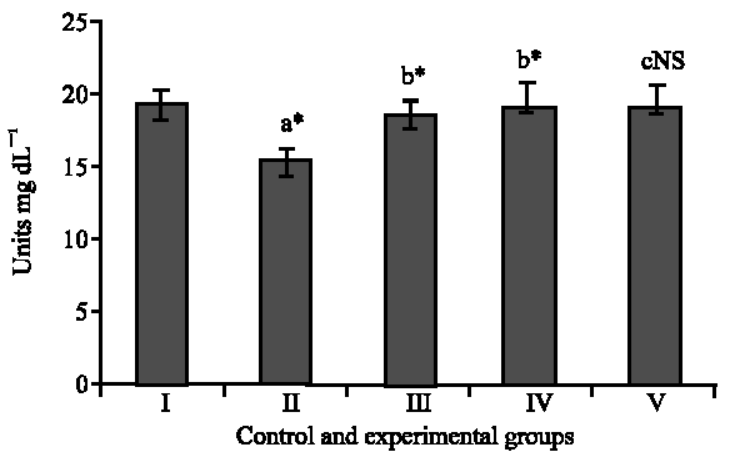

Fig. 1: Levels of blood urea in control and experimental groups. Values are given as mean $\pm \mathrm{SD}$ for groups of 6 rats each. a: Group II vs. Group I, b: Group III and IV vs. Group II, c: Group V vs. Group I. *: Thestatistical significance at $\mathrm{p}<0.05$; NS: NonSignificant 


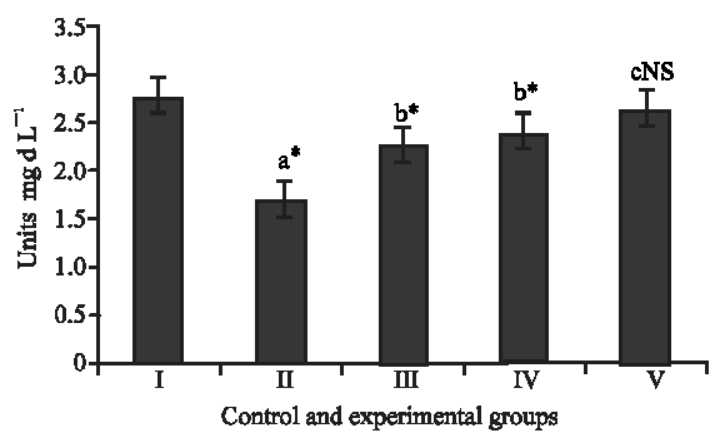

Fig. 2: Levels of Serum uric acid in control and experimental groups. Values are given as mean \pm SD for groups of 6 rats each. a: Group II vs. Group I, b: Group III and IV vs. Group II, c: Group V vs. Group I. *: The statistical significance at $\mathrm{p}<0.05$; NS: Non-Significant

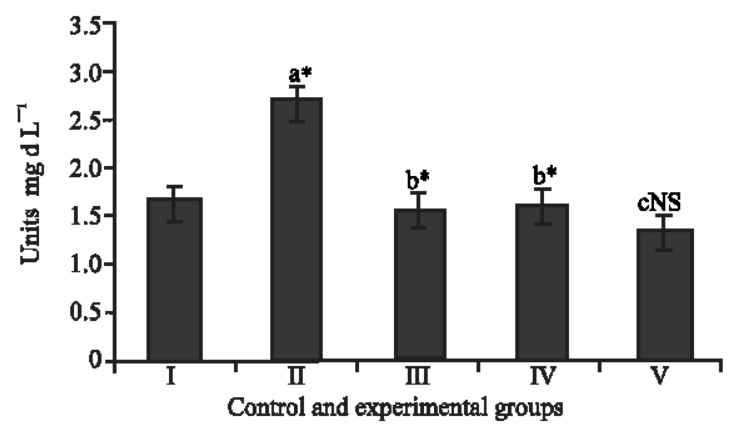

Fig. 3: Levels of Serum Creatinine in control and experimental groups. Values are given as mean \pm SD for groups of 6 rats each. a: Group II vs. Group I, b: Group III and IV vs. Group II, c: Group V vs. Group I. *: The statistical significance at $\mathrm{p}<0.05$, NS: Non-Significant

increased in Group II cancer induced animals. Whereas, the drug treated Group III and IV showed slightly reduced creatinine levels. In drug alone group, the creatinine level is similar to control group (Fig. 3).

Effect of fungal taxol on the levels of triglycerides, cholesterol and phospholipids in control and experimental groups: The levels of lipid components such as Triglycerides (TG), Total Cholesterol (TC) and Phospholipids (PL) in control and experimental group of rats (Fig. 4).

There was a significant increase in the levels of $\mathrm{TG}$, TC and PL in mammary carcinoma bearing (Group II) rats when compared with control (Group I) rats. In drug treated (Group III) and authentic taxol treated (Group IV), the levels of TG, TC and PL

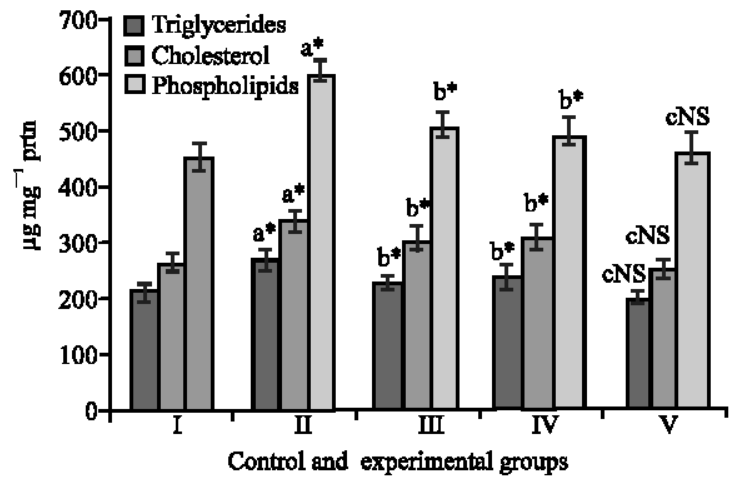

Fig. 4: Levels of Triglycerides, Cholesterol and Phospholipids in control and experimental groups. Values are given as mean \pm SD for groups of 6 rats each. a: Group II vs. Group I, b: Group III and IV vs. Group II, c: Group V vs. Group I. *: The statistical significance at $\mathrm{p}<0.05$; NS: NonSignificant

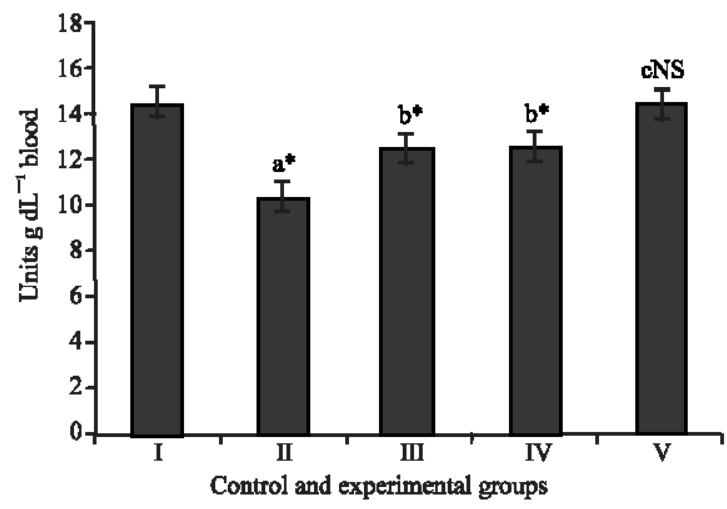

Fig. 5: Levels of Haemoglobin in control and experimental groups. Values are given as mean \pm SD for groups of 6 rats each. a: Group II vs. Group I, b: Group III and IV vs. Group II, c: Group V vs. Group I. *: The statistical significance at $\mathrm{p}<0.05$; NS- Non Significant

were significantly decreased when compared with cancer bearing (Group II) rats. Non-significant variations were observed in drug control (Group V) rats when compared with normal (Group I) rats.

Effect of fungal taxol on the levels of haemoglobin and total protein in control and experimental groups: The levels of haemoglobin were clearly shown in Fig. 5. Haemoglobin levels were significantly reduced in Group II cancer induced animals. The levels were increased in fungal taxol and commercial taxol treated animals (Group III and IV). Whereas, the 


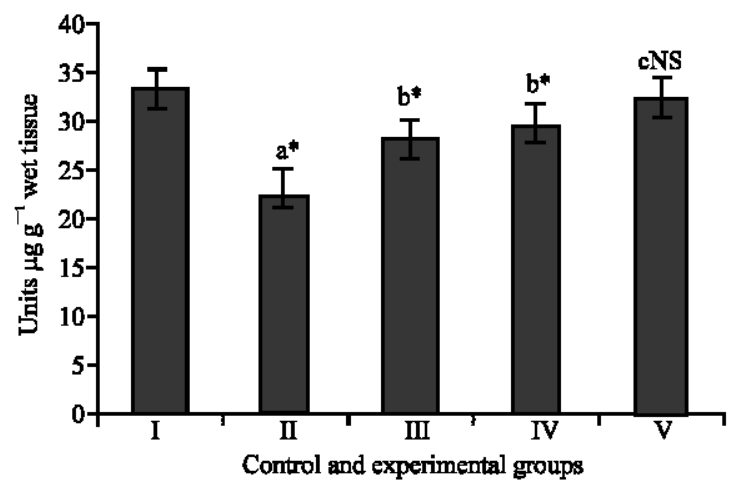

Fig. 6: Levels of protein in control and experimen tal groups. Values are given as mean \pm SD for groups of 6 rats each. a: Group II vs. Group I, b: Group III and IV vs. Group II, c: Group V vs. Group I. *: Statistical significance at $\mathrm{p}<0.05, \mathrm{NS}$ : NonSignificant

Group V drug alone rats the haemoglobin levels were similar to the control groups. Total protein content has been shown in Fig. 6. The protein content was reduced in cancer bearing animals. The protein level was significantly increased in Group III and IV and appears very near to normal. There is no significant difference in control and drug alone group of rats.

\section{Histopathological changes in liver tissue in control and} experimental groups: In normal control (Group I) rats, the liver showed normal architecture with lobular configuration and central vein surrounded by cords of hepatocytes (Fig. 7a).

In the liver of mammary carcinoma bearing (Group II) rats shows focal inflammatory collections around portal traids and lymphocytes in sinusoids and hydropic degeneration of hepatocytes (Fig. $7 \mathrm{~b}$ ).
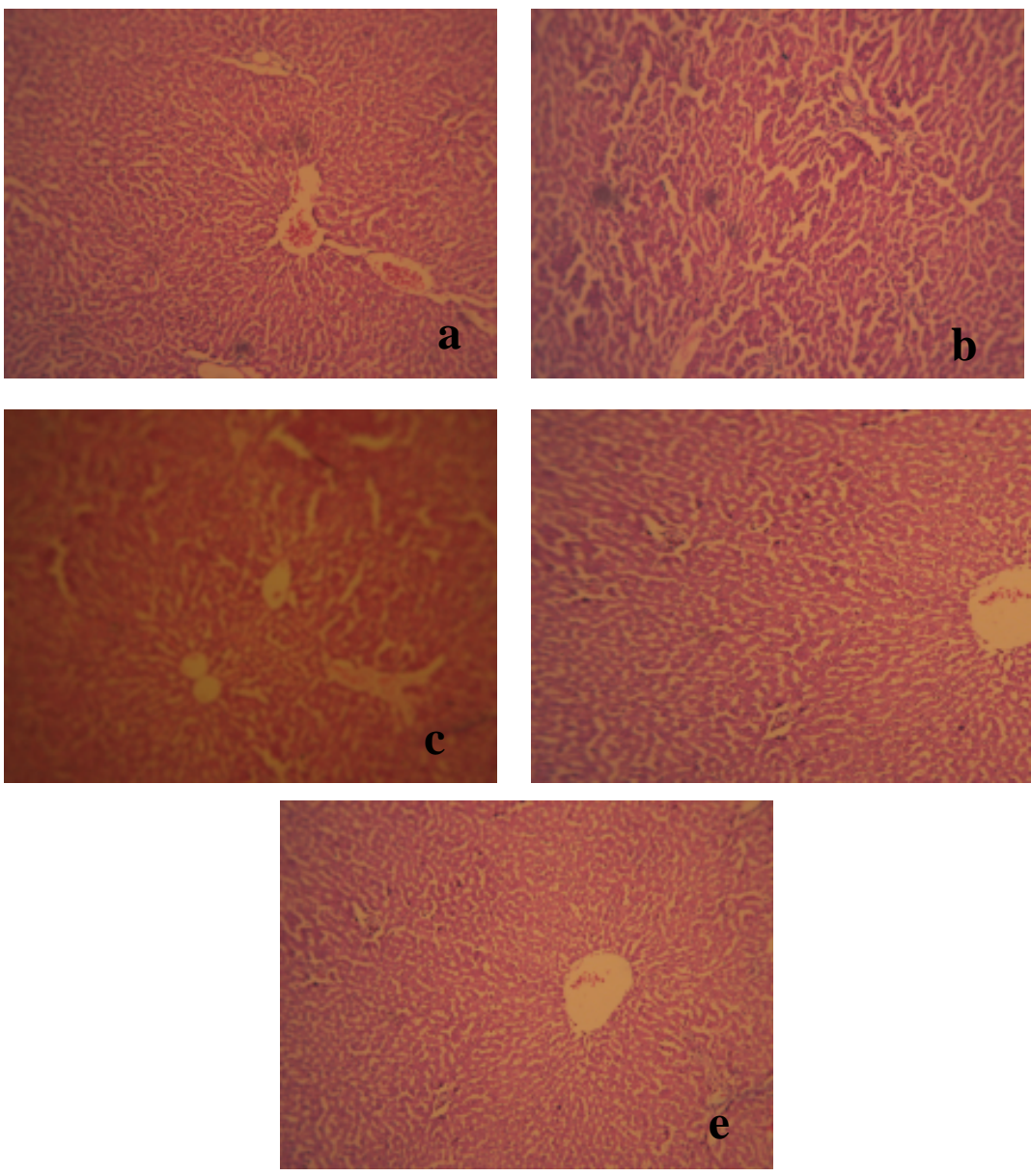

Fig. 7: Histopathological examination of liver tissue in control and tumor bearing animals treated with fungal taxol. a: Tissue of normal rat, b: Cancer-induced breast tissue of rat, c: Cancer-induced rat treated with fungal taxol, $d$ : Cancer-induced rat treated with taxol, e: Rat treated with fungal taxol alone 

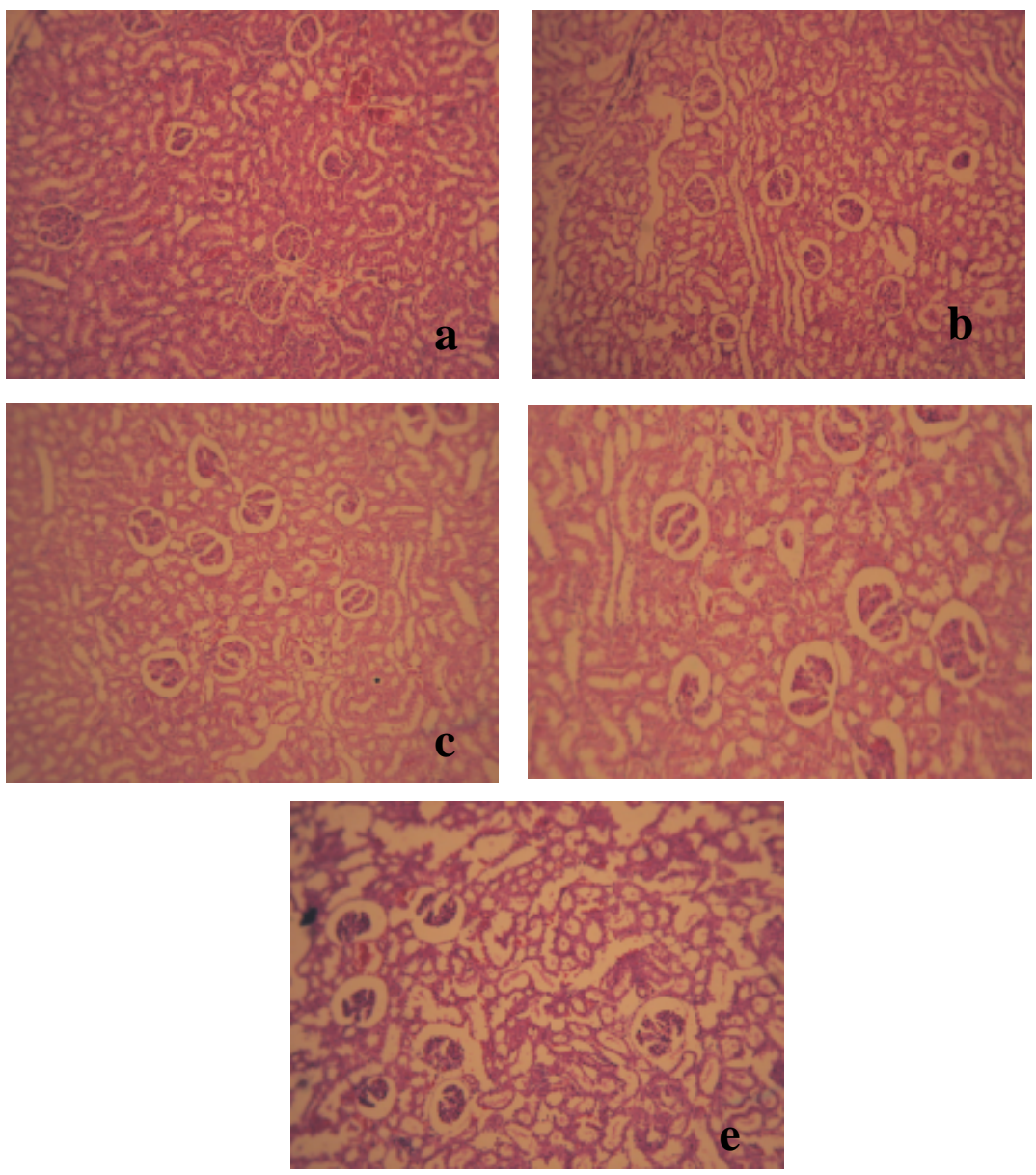

Fig. 8: Histopathological examination of kidney tissue in control and tumor bearing animals treated with fungal taxol. a: Tissue of normal rat, $\mathrm{b}$ : Cancer-induced breast tissue of rat, $\mathrm{c}$ : Cancer-induced rat treated with fungal taxol, $\mathrm{d}$ : Cancer-induced rat treated with taxol, e: Rat treated with fungal taxol alone

In fungal taxol (Fig. 7c) and commercial taxol treated (Fig. 7d) (Group III and IV) animals showed normal hepatocytes. Drug control (Group V) animals, showed normal morphology without any abnormal changes (Fig. 7e).

Histopathological changes in kidney tissue in control and experimental groups: In normal control rats (Group I), the kidney showed normal glomerulus and tubules (Fig. 8a).

The kidney of cancer induced (Group II) animals shows glomeruli appear congested, tubules appear dilated with focal epithelial damage (Fig. 8b). In fungal taxol (Fig. 8c) and commercial taxol treated (Fig. 8d) (Group III and IV) animals, kidney showed mild dilated tubules and congested glomeruli. The drug control (Group V) animals showed normal tubules without any toxic changes and with normal glomeruli (Fig. 8e).

\section{DISCUSSION}

Paclitaxel (taxol) is the most effective antitumor agent developed in the past three decades. It has been used for effective treatment of a variety of cancers including refractory ovarian cancer, breast cancer, nonsmall cell lung cancer, AIDS related Kaposi's sarcoma, head and neck carcinoma and other cancers (Wani et al., 1971; Wall et al., 1976; Croom, 1995). The present study was carried to evaluate the anticancer activity of fungal taxol isolated from Pestalotiopsis pauciseta VM1 Sacc. on mammary tumor bearing Sprague Dawley rats. Blood urea, serum uric acid and creatinine levels were significantly reduced in Group II cancer induced animals. The levels were increased in fungal taxol and commercial taxol treated animals (Group III and IV). Whereas, in (Group V) drug alone rats the levels of blood urea, serum uric acid and creatinine levels were similar to the control groups. The 
amount of urea excreted depends upon the glomerular filtration rate and when this excretion fails to balance the production, plasma level rises. Serum creatinine is an index for renal function. It is produced endogenously by tissue creatinine breakdown and an increase in serum creatinine may be due to the tissue damage. The amount of creatinine excreted depends on the glomerular filtration rate, when this excretion fails to balance the production, serum creatinine rises (Nosaka et al., 1992).

When the animals were given fungal taxol, the elevated levels of blood urea and serum creatinine were almost brought back to near normal level, thus proving its beneficial role on fungal taxol induced nephro toxicity. Uric acid, the metabolic end product of purine metabolism has proven to be a selective antioxidant, capable especially of reacting with hydroxyl radicals and hydrochlorus acid (Hasugawa and Kuroda, 1989). The reduced level of uric acid in breast cancer may be due to increased utilization of uric acid against lipid peroxide which is a characteristic feature of cancer condition. Increased uric acid level observed after the treatment of fungal taxol may be due to the decreased tumor burden.

Breast cancer bearing animal shows less content of haemoglobin. This may be due to decrease in RBC number which indicates anaemic induction (Sarathchandra et al., 1996). Total protein content was reduced in cancer bearing animals. The protein level was significantly increased in Group III and IV and they are very near to normal. There is no significant difference in control and drug alone group of rats. This may be due to cytoprotective and cytostabilizing property of the drug.

Cancer cachexia is associated with higher lipid mobililsing activity (Beck and Risdale, 1991) and cholesterol metabolism is regulated differently during tumour growth (Dessi et al., 1995). Elevated cholesterol level precedes the observed changes in DNA and protein content suggested a link between cholesterol and DNA synthesis pathway (Rao, 1995). Deregulated cholesterogenesis observed in tumors implicated an over production that could result in the enrichment of tumor cell membrane with cholesterol (Dessi et al., 1992). Abnormal levels of lipid profile and their changes in lipid metabolising enzymes are proportionate to the disease stage. Mitochondrial membrane contains phospholipids and cholesterol and they are the second largest organelles in the cell (Parsons and Yano, 1967). Dessi et al. (1992) reported that rats develop marked changes in the level and distribution of total cholesterol during tumour growth. The progression and proliferation on tumour cells depends on elevation of cholesterol and phospholipids levels which modifies the lipid fluidity of tumour cell membrane increasing the rate of malignancy in cancerous conditions. In the present study, there was a significant increase in the levels of Triglycerides (TG), Total Cholesterol (TC) and Phospholipids (PL) in mammary carcinoma bearing (Group II) rats when compared with control (Group I) rats. On drug treated (Group III) and authentic taxol treated (Group IV) rats, the levels of TG; $\mathrm{TC}$ and PL were significantly decreased when compared with induced (Group II) rats. Non-significant variations were observed in drug control (Group V) rats when compared with normal (Group I) rats.

\section{CONCLUSION}

The present studies are supporting as fungal taxol has shown improvement in the biochemical parameters of the hosts. The above parameters are responsible for the anticancer activity of fungal taxol isolated from Pestalotiopsis pauciseta VM1.

\section{ACKNOWLEDGEMENTS}

The researchers thank Dr. N. Anand, former Director and Dr. R. Rangasamy, Director, Centre for Advanced Studies in Botany, University of Madras for the laboratory facilities provided.

\section{REFERENCES}

Beck, S.A. and M.J. Risdale, 1991. Lipid mobilizing factors specially associated with cancer cachexia. $\mathrm{Br}$. J. Cancer, 63: 846-850.

Caraway, W.T., 1963. Uric Acid. In: Standard Methods of Clinical Chemistry, 4th Edn., Seligson, D. (Ed.). Academic Press, New York, pp: 239-247.

Croom, E.M., 1995. Taxus for Taxol and Toxoids. CRC, Boca Raton, FL, pp: 37-70.

Dessi, S., B. Batetta, C. Anchisi, P. Pani, P. Costelli, L. Tessitore and F.M. Baccino, 1992. Cholesterol metabolism during the growth of a rat ascites hepatoma (Yoshida AH-130). Br. J. Cancer, 66: 787-793.

Dessi, S., B. Batetta, O. Spano, G.J. Begby and L. Tessitore et al., 1995. Perturbations of triglycerates but not of cholesterol metabolism are prevented by anti-tumour necrosis factor treatment in rats bearing and ascites hepatoma (hepatoma $\mathrm{AH}$ 130). Br. J. Cancer, 72: 1135-1143.

Drabkin, D.H. and J.H. Austin, 1932. Spectrophotometric studies, spectrophotometric constants for common haemoglobin derivates in humans, dogs and rabbial bloods. J. Biol. Chem., 98: 719-735.

Hasugawa, T. and M. Kuroda, 1989. A new role of uric acid as antioxidant in human plasma. Jap. J. Clin. Pathol., 37: 1020-1027. 
Kumaraguruparan, R., P.B. Seshagiri, T. Hara and S. Nagini, 2007. Chemoprevention of rat mammary carcinogenesis by black tea polyphenols: Modulation of xenobiotic-metabolizing enzymes, oxidative stress, cell proliferation, apoptosis and angiogenesis. Mol. Carcinogen., 46: 797-806.

Li, J.Y., R.S. Sidhu, E. Ford, W.M. Hess and G.A. Strobel, 1998a. The induction of taxol production in the endophytic fungus-Periconia sp. from Torreya grandifolia. J. Ind. Microbiol., 20: 259-264.

Li, J.Y., R.S. Sidhu, A. Bollon and G.A. Strobel, 1998 b. Stimulation of taxol production in liquid cultures of Pestalotiopsis microspora. Mycol. Res., 102: 461-464.

Natelson, S., M.L. Scott and C. Beffna, 1951. A rapid method for the estimation of urea in biological fluids by means of the reaction between diacetyl and urea. Am. J. Clin. Pathol., 21: 275-281.

Nosaka, K., J. Nakada and H. Endou, 1992. Cisplatininduced alterations in renal structure, ammoniagenesis and glucogenesis of rats. Kidney Int., 41: 73-79.

Parekh, A.C. and D.H. Jung, 1970. Cholesterol determination with ferric acetate-uranyl acetate and sulphuric acid-ferrous sulphate reagents. Anal. Chem., 42: 1423-1427.

Parsons, D.F. and Y. Yano, 1967. The cholesterol content of the outer and inner membrane of guinea-pig liver mitochondria. Biochim. Biophys. Acta, 135: 362-364.

Rao, K.N., 1995. The significance of cholesterol biosynthetic pathway in cell growth and carcinogenesis. Anticancer Res., 15: 309-314.

Rice, E.W., 1970. Triglycerides in Serum. In: Standard Methods of Clinical Chemistry, Roderick, P. and C.H. MacDonald (Eds.). 6th Edn., Academic Press, New York, pp: 215-222.
Rouser, G., S. Fleisher and A. Yamanoto, 1970. Two dimensional thin layer chromatographic separation of polar lipids and determination of phospholipids by phosphorus analysis of spots. Lipids, 5: 494-496.

Sarathchandra, G., J. Chandra, S. Jayasundar and P.B. Murthy, 1996. Toxicology of Cleistanthus collinus, an indigenous plant acute toxicity study. Ind. J. Toxicol., 3: 9-17.

Slot, C., 1965. Creatine determination: A new and specific Jaffe's reaction method. Scandinavian J. Clin. Lab. Invest., 17: 381-387.

Stierle, A., G.A. Strobel and D. Stierle, 1993. Taxol and taxane production by Taxomyces andreanae. Science, 260: 214-216.

Strobel, G., X. Yang, J. Sears, R. Kramer, R.S. Sidhu and W.M. Hess, 1996. Taxol from Pestalotiopsis microspora, an endophytic fungus of Taxus wallichiana. Microbiology, 142: 435-440.

Van Handel, E., 1961. Modification of the microdeterminating triglycerides. Clin. Chem., 7: 249-257.

Wall, M.E., W.C. Wani and H.L. Taylor, 1976. Isolation and chemical characterization of antitumour agents from plants. Cancer Treat Rep., 60: 1011-1030.

Wani, M.C., H.L. Taylor, M.E. Wall, P. Goggon and A.T. McPhail, 1971. Plant antitumour agents. VI The isolation and structure of Taxol, a novel antileukemic and antitumour agent from Taxus brevifolia. J. Am. Chem. Soc., 93: 2325-2327.

Welsch, C.W., 1985. Host factors affecting the growth of carcinogen induced rat mammary carcinomas: A review and tribute to Charles Brenton Huggins. Cancer Res., 45: 3415-3443. 